\title{
Sellar Chondroid Chordoma
}

National Cancer Institute

\section{Source}

National Cancer Institute. Sellar Chondroid Chordoma. NCI Thesaurus. Code C155782.

A chondroid chordoma that arises from the sellar region. 